\title{
Synthesis of Promising Cathode Material for Lithium Polymer Batteries
}

\author{
Sergey Smirnov ${ }^{1}$, Ivan Putsylov ${ }^{1}$, Sergey Fateev ${ }^{1, *}$, Vladimir Zhorin ${ }^{2}$, Alexander Kartushin ${ }^{1}$ \\ ${ }^{1}$ National Research University "Moscow Power Engineering Institute", Department of Chemistry and electrochemical energetic, 111250 \\ Moscow, Russia \\ ${ }^{2}$ Semenov Institute of Chemical Physics, Laboratory of reactionary capable oligomers chemistry and multifunctional light-sensitive \\ materials, 4 Kosy gina Street 1, 119991 Moscow, Russia
}

\begin{abstract}
Original method for synthesis of lithium vanadium phosphate was developed. The method includes two stages: 1st, synthesis of iron phosphate from a mixture of ammonium dihydrophosphate and metal oxide; and 2st, synthesis of lithium vanadium phosphate by thermal lithiation of the product obtained in the 1st stage, with mechanical activation of the precursor in the course of plastic deformation. Our results would provide some basis for further improvement on the $\mathrm{Li}_{3} \mathrm{~V}_{2}\left(\mathrm{PO}_{4}\right)_{3}$ electrode materials for advance lithium-ion batteries.
\end{abstract}

\section{Introduction}

The modern energy, in particular, hydrogen, requires the development of new efficient storage systems of energy generation and accumulating. The electricity accumulation to create power plants based on renewable energy sources (RES) is relevant due to the variability derived energy. The energy storage generated by small power plants for the subsequent smoothing of peak loads is very important task. In addition to small and large energy, a significant need for highly efficient gen erators of electric ity and batteries demand on transport, portable (mobile phones, gadgets, laptops, etc.) technology, aviation, space and other fields [1-3]. For the autonomous wind and solar power sources it is appropriate to use electrochemical batteries. They are mostly limit the cost performance, reliability and efficiency of wind and solar power plants with a capacity up to $100 \mathrm{~kW}$. At the moment lithium poly mer batteries are the most promising rechargeable chemical current sources: they dominate due to their light weight, high density electrical energy.

Recently, the demand for lithiu m poly mer battery has increased, which is due both to the tendency toward miniaturization of electronic boards and to the increased requirements imposed by power consumers [4-7]. The development of lithium polymer battery substantially expands the opportunities of modern miniature devices, such as smart cards, implanted medical devices, me mory units, various sensors, and converters. One of the main difficulties in creation of film batteries consists in development of efficient cathode materials.

Frame work cathode materials based on the phosphate polyanion, such as $\mathrm{LiFePO}_{4}, \mathrm{LiMnPO}_{4}, \mathrm{LiVPO}_{4} \mathrm{~F}$, $\mathrm{Li}_{3} \mathrm{~V}_{2}\left(\mathrm{PO}_{4}\right)_{3}$ and others with favorable thermal stability, have attracted much attention in recent years $[8,9]$.
Particularly, monoclinic $\mathrm{Li}_{3} \mathrm{~V}_{2}\left(\mathrm{PO}_{4}\right)_{3}$ has emerged as one of the promising cathode candidates for high power lithium-ion batteries due to its high theoretical capacity, high operate voltage $(3.6 \mathrm{~V}, 4.1 \mathrm{~V})$ and good ion mobility [10]. The large interstitial spaces created by units allows fast ion migration in three dimensions, and three reversible lithium ions can be totally extracted from the lattice of $\mathrm{Li}_{3} \mathrm{~V}_{2}\left(\mathrm{PO}_{4}\right)_{3}$ with in a range of 3.0 and 4.8 V with the highest theoretical capacity of 197 $\mathrm{mA} * \mathrm{~h} / \mathrm{g}$ obtained . However, the power performance of $\mathrm{Li}_{3} \mathrm{~V}_{2}\left(\mathrm{PO}_{4}\right)_{3}$ is seriously limited by the poor electronic conductivity $\left(2.4 \times 10^{-7} \mathrm{~S} / \mathrm{cm}\right)$.

Up to now, tremendous effective approaches have been investigated to overcome these obstacles by minimizing the particle size, coating with carbon and doping with metal ions [10].

In the methods known from the literature, synthesis of lithium metal phosphates is a double-stage thermal synthesis of ternary mixtures: ammonium dihydrophosphate, metal oxide, and lithium compounds. However, it has been found that its mechanis $m$ is rather complicated and presumably includes several parallel processes. Therefore, the following two-stage process model has been suggested: 1st, synthesis of metalphosphate from a mixture of ammonium dihydrophosphate; and 2nd, synthesis of lithium metal phosphate by thermal lithiation of the product obtained in the 1st stage [6,8].

It has been shown previously that the mechanical activation of a precursor in a high-pressure apparatus of the Bridgman anvil type can be successfully used to synthesize highly dispersed cathode materials for lithium batteries [11-13]. Therefore, we studied the effect of mechanical activation on synthesis and electrochemical properties of lithium vanadium phosphate.

\footnotetext{
* Corresponding author: serfat@list.ru
} 


\section{Experimental section}

We chose $\mathrm{NH}_{4} \mathrm{H}_{2} \mathrm{PO}_{4}, \mathrm{Li}_{2} \mathrm{CO}_{3}$, and $\mathrm{V}_{2} \mathrm{O}_{3}$ of chemically pure grade as objects of study. Starting mixtures of powdered components were prepared by mixing in a mortar. In the first stage of synthesis, a mixture of $\mathrm{NH}_{4} \mathrm{H}_{2} \mathrm{PO}_{4}$ and $\mathrm{V}_{2} \mathrm{O}_{3}$ was annealed in a muffle furnace at a temperature of $750^{\circ} \mathrm{C}$ for $6 \mathrm{~h}$. In the second stage, $20 \%$ $\mathrm{Li}_{2} \mathrm{CO}_{3}$ was added to the product obtained and the mixture was thermally treated at temperatures of 600 , 700 , and $800^{\circ} \mathrm{C}$ for $4-10 \mathrm{~h}$. The plastic deformation of the precursors under a pressure of $1.5 \mathrm{GPa}$ was performed at room temperature on anvils made of a VK6 hard alloy, with the working surfaces of the anvils having a diameter of $15 \mathrm{~mm}$ and anvil rotation angle equal to $300^{\circ}$. The heat effects that occur in the prepared materials at temperatures from room temperature to $800^{\circ} \mathrm{C}$ were studied by scanning differential calorimetry on a TA Instruments model Q100 instrument at a scanning rate of $20 \mathrm{~K}^{*} \min ^{-1}$; the sample weight was from 1 to $3 \mathrm{mg}$. Thermogravimetric analysis was performed on TA Instrument model Q500 thermogravimetric analyzer; the scan rate was 20 $\mathrm{K}^{*} \min ^{-1}$ and the sample weight was $2-4 \mathrm{mg}$. X-ray diffraction (XRD) measurements were performed on an Empyrean diffractometer using $\mathrm{CuK}$ radiation (two wavelengths - 1.5406 and $1.5444 \mathrm{E}$ were used for calculations, considering a 2:1 ratio of their intensities in the doublet) and scanning over a $2 \Theta$ range of $5^{\circ}-100^{\circ}$. The calculated phase composition was verified by dual phase Rietveld refinement using the MRIA software program [14].

A composite electrode was prepared by mixing 80 wt $\% \quad \mathrm{Li}_{3} \mathrm{~V}_{2}\left(\mathrm{PO}_{4}\right)_{3}, \quad 10 \mathrm{wt} \% \quad \mathrm{PVDF}$ and $10 \mathrm{wt} \%$ acetylene black with NMP (1-methyl-2-pyrrolidone) to form the slurry, which was then spread on to a alu minum foil and dried at $120^{\circ} \mathrm{C}$ for $24 \mathrm{~h}$ in a vacuum oven. The batteries were assembled in an argon-filled gloved-box, in which oxygen and mo is ture level less than $1 \mathrm{ppm}$, and the electrolyte was $1 \mathrm{M} \mathrm{LiPF} 6$ in a mixture of EC (ethylene carbonate), DMC (dimethyl carbonate) and EMC (ethylmethyl carbonate) (1:1:1 by weight). Typically, a working electrode of $1.5 \mathrm{~cm}^{2}$ was prepared with the active material mass loading of $3.0 \mathrm{mg}$ per $\mathrm{cm}^{2}$. The coin cell was fabricated using the lithium metal as a counter electrode. Electrochemical measurements were conducted with galvanostatic charge and discharge on a Elins P-20X8 cell testing apparatus in the voltage range of $3.0-4.3 \mathrm{~V}$ at room temperature. The discharge-rate range is from 0.5 to $1 \mathrm{C}$ to $3.0 \mathrm{~V}$ and charge is at $0.5 \mathrm{C}$ to $4.3 \mathrm{~V}$. The $\mathrm{C}$-rates and storage capacities were calculated from the mass of $\mathrm{Li}_{3} \mathrm{~V}_{2}\left(\mathrm{PO}_{4}\right)_{3}$ with the amount of carbon being subtracted $(1 \mathrm{C}=130 \mathrm{~mA} * \mathrm{~h} / \mathrm{g})$. Cyclic voltammetry $(\mathrm{CV})$ measurements were performed on a Elins P-20X8 electrochemical workstation. CVs were conducted in the cut-off voltage range of $3.0-4.3 \mathrm{~V}$ versus $\mathrm{Li} / \mathrm{Li}^{+}$at a scan rate of $0.1 \mathrm{mV} / \mathrm{s}$.

\section{Results and discussion}

The thermogravimetric curves for the initial mixture of $\mathrm{V}_{2} \mathrm{O}_{3}$ and $\mathrm{NH}_{4} \mathrm{H}_{2} \mathrm{PO}_{4}$ and the same mixture after being subjected to mechanical activation were similar. In both cases, we observed a process spanning the temperature range of $100-800^{\circ} \mathrm{C}$ featuring a characteristic exothermic peak (Fig. 1). The enthalpy associated with the exothermic peak was 2177 and $2519 \mathrm{~J} / \mathrm{g}$ for the initial mixture and for the mechanically activated one, respectively. The exothermic processes in the specimens being heated were accompanied by the decrease in sample weight by 30.9 and $32.1 \%$ for the initial mixture and for the mechanically activated one, respectively (Fig. 2).

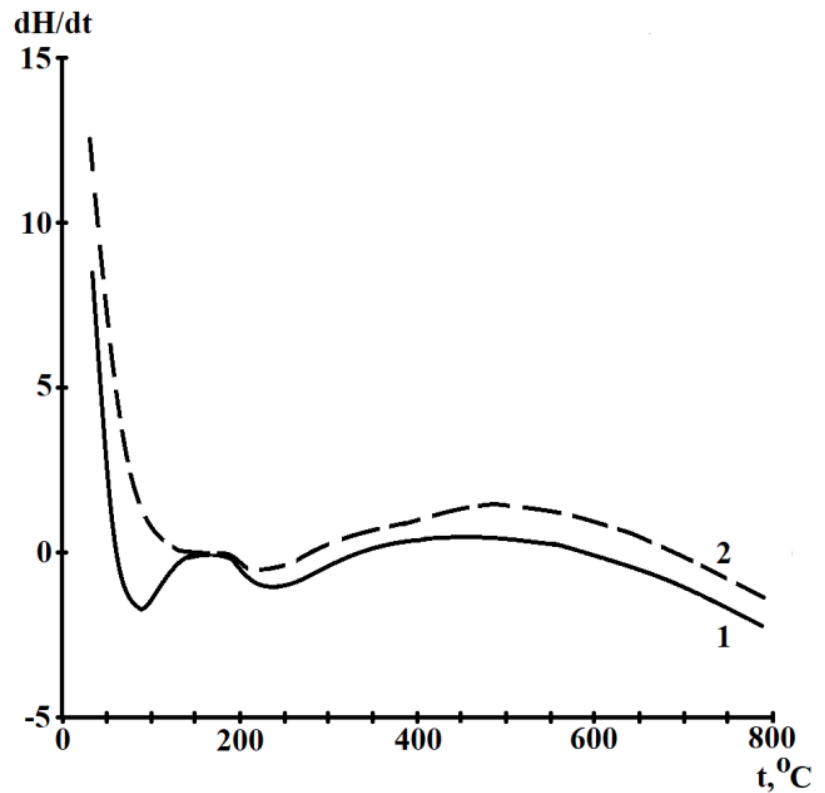

Fig. 1. Sample derivatograms $\mathrm{NH}_{4} \mathrm{H}_{2} \mathrm{PO}_{4}+\mathrm{V}_{2} \mathrm{O}_{3}$ : 1-initial mixture, 2 - after plastic deformation

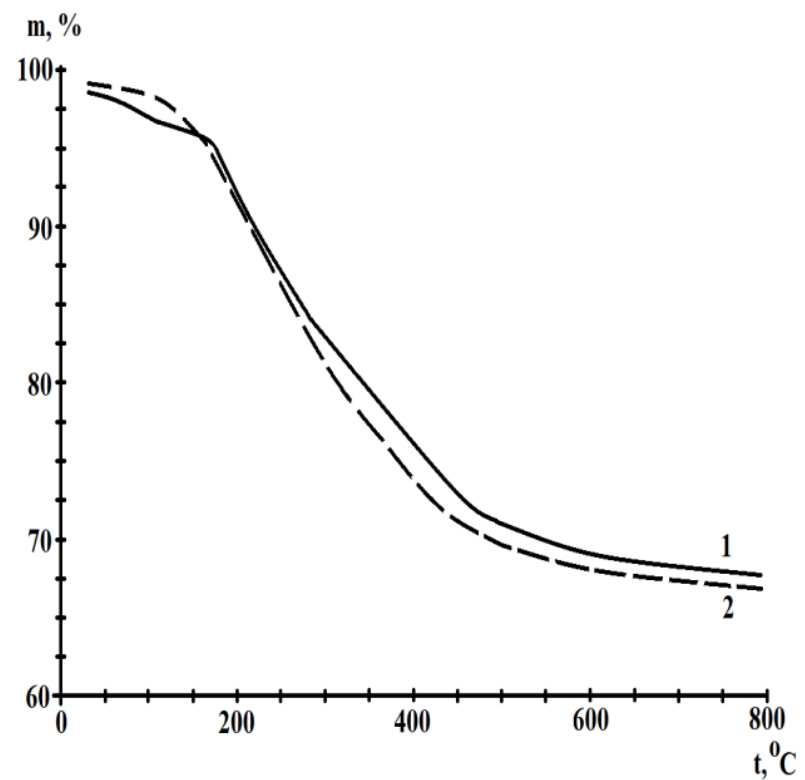

Fig. 2. Thermograms of samples $\mathrm{NH}_{4} \mathrm{H}_{2} \mathrm{PO}_{4}+\mathrm{V}_{2} \mathrm{O}_{3}$ : 1-initial mixture, 2 - after plastic deformation

A diffractogram of the starting mixture of $\mathrm{V}_{2} \mathrm{O}_{3}$ and $\mathrm{NH}_{4} \mathrm{H}_{2} \mathrm{PO}_{4}$ and treated under pressure were almost identical. Based on the results of two-phase refinement 
by the Rietveld method [8] for the phases $\mathrm{VPO}_{4}: \mathrm{V}_{2} \mathrm{O}_{3}$, the following ratios were obtained: 11: 1 (Fig. 3).

The thermogravimetric curves for the initial mixture of $\mathrm{VPO}_{4}$ and $\mathrm{Li}_{2} \mathrm{CO}_{3}$ and the same mixture after being subjected to mechanical activation were similar. In both cases, we observed a process spanning the temperature range of $150-800^{\circ} \mathrm{C}$ featuring a characteristic exothermic peak (Fig. 4). The enthalpy associated with the exothermic peak was 3796 and $3946 \mathrm{~J} / \mathrm{g}$ for the initial mixture and for the mechanically activated one, respectively. The exothermic processes in the specimens being heated were accompanied by the decrease in sample weight by 17.4 and $15.6 \%$ for the in itial mixture and for the mechanically activated one, respectively (Fig. 5).

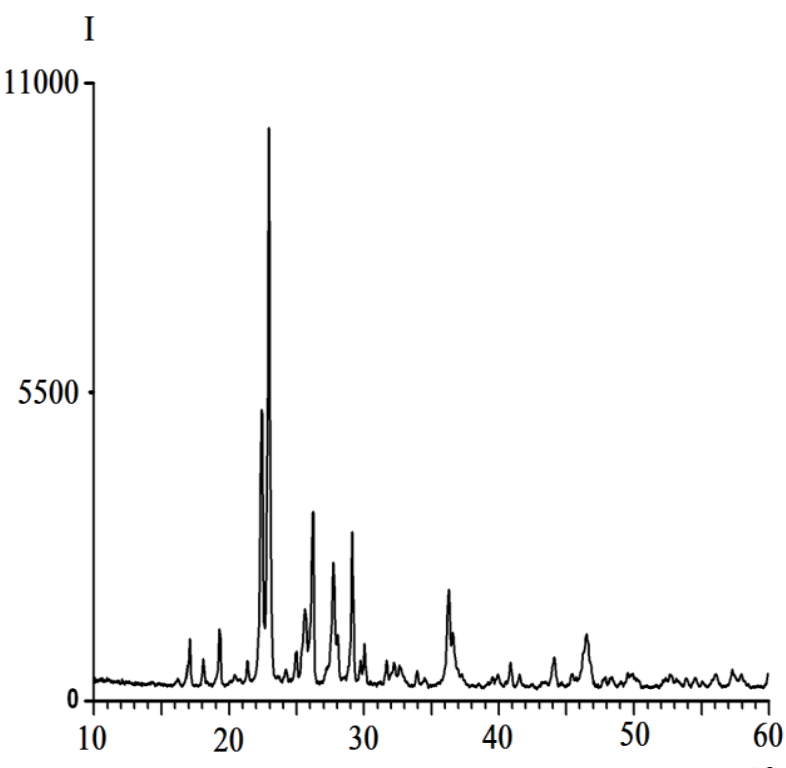

Fig. 3. X-ray diffraction pattern of lithium vanadium phosphate

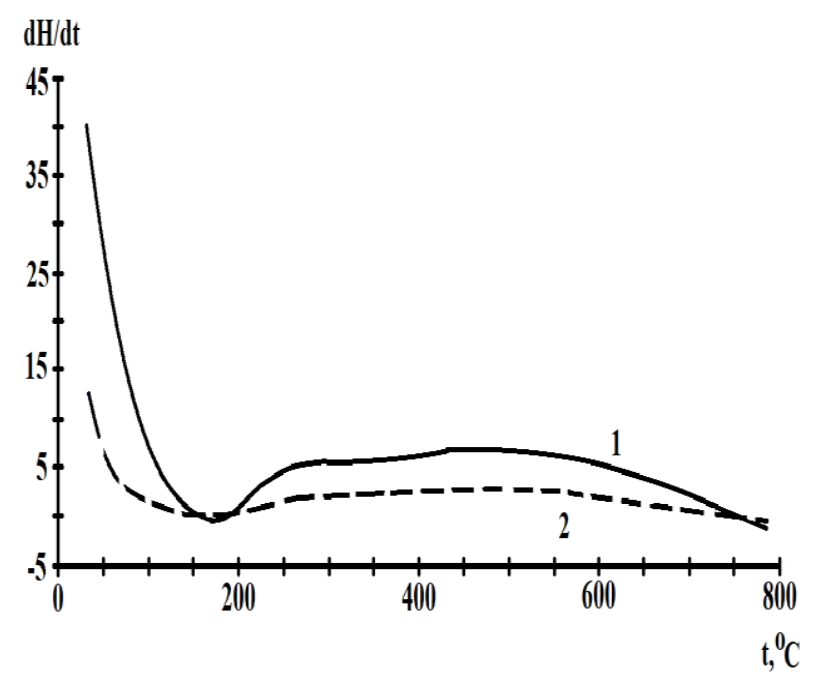

Fig. 4. Sample derivatograms $\mathrm{VPO}_{4}+\mathrm{Li}_{2} \mathrm{CO}_{3:} 1$ initial mixture, 2 - after plastic deformation

For the initial mixture, weight loss occurred as a onestep process, and a major fraction of the sample weight was lost with in the range of temperature of 200 to $650^{\circ} \mathrm{C}$. For the mechanically activated sample, weight loss started $30^{\circ} \mathrm{C}$ lower and ended $50^{\circ} \mathrm{C}$ lower compared to the initial mixture. This difference can be explained by the fact that the chemical reactions partially occurred during mechanical activation. Structurization processes, which may not exhibit associated heat effects, can proceed in parallel with the physicochemical processes in our samples.

We identified four peaks of $\mathrm{Li}_{3} \mathrm{~V}_{2}\left(\mathrm{PO}_{4}\right)_{3}$ and $\mathrm{LiVP}_{2} \mathrm{O}_{7}$ peaks in XRD patterns of the initial $\mathrm{VPO}_{4}-$ $\mathrm{Li}_{2} \mathrm{CO}_{3}$ mixture annealed at $700^{\circ} \mathrm{C}$ for $10 \mathrm{~h}$. By applying dual phase Rietveld refinement to our XRD data [8], we established that the phase ratio $\mathrm{Li}_{3} \mathrm{~V}_{2}\left(\mathrm{PO}_{4}\right)_{3}: \mathrm{LiVP}_{2} \mathrm{O}_{7}$ was $8: 2$ for the initial mixture and $9: 1$ for the mixture annealed at $800^{\circ} \mathrm{C}$ for $6 \mathrm{~h}$. It was found that the plastic deformation of the precursor is effective in the second stage of $\mathrm{Li}_{3} \mathrm{~V}_{2}\left(\mathrm{PO}_{4}\right)_{3}$ synthes is. XRD patterns of samples subjected to mechanical activation and annealing at $600^{\circ} \mathrm{C}$ for $7 \mathrm{~h}$ featured peaks due to $\mathrm{Li}_{3} \mathrm{~V}_{2}\left(\mathrm{PO}_{4}\right)_{3}$ and $\mathrm{LiVP}_{2} \mathrm{O}_{7}$ phases, as shown in Fig. 6. Applying dual phase Rietveld refinement yielded the phase ratio $\mathrm{Li}_{3} \mathrm{~V}_{2}\left(\mathrm{PO}_{4}\right)_{3}: \mathrm{LiVP}_{2} \mathrm{O}_{7}=9: 1$. With annealing temperatures raised to $750^{\circ} \mathrm{C}(4 \mathrm{~h})$ the phase ratio was 11:1.

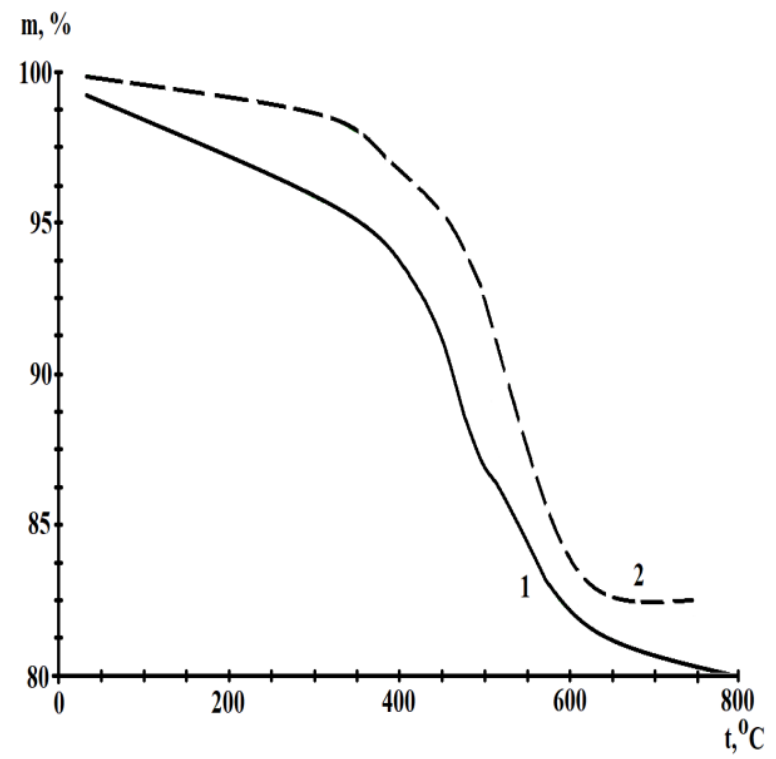

Fig. 5. Thermograms of samples $\mathrm{VPO}_{4}+\mathrm{Li}_{2} \mathrm{CO}_{3}$ : 1-initial mixture, 2 - after plastic deformation

Using the Debye-Scherrer formula, we estimated the sizes of the coherent scattering domain for the main phase $\left(\mathrm{Li}_{3} \mathrm{~V}_{2}\left(\mathrm{PO}_{4}\right)_{3}\right): 90 \mathrm{~nm}$ for samples annealed at $750^{\circ} \mathrm{C}, 60 \mathrm{~nm}$ for annealing at $600^{\circ} \mathrm{C}$. It is known from reports of other authors that $\mathrm{Li}_{3} \mathrm{~V}_{2}\left(\mathrm{PO}_{4}\right)_{3}$ are formed in prolonged (20-25h) multistage synthesis at a final temperature of $750-900^{\circ} \mathrm{C} \quad[5,9,10]$.

We thus see that the mechanical activation of the precursor in the Bridgman anvil apparatus shortened the annealing time required to achieve the desired nanodispersed material. We explain these results by considering the following processes. Plastic deformation induces numerous structural defects in individual solids with different chemical natures. These processes are 
particularly active in binary mixtures; namely, mass transfer processes resulting in the formation of solid solutions are very intense under these conditions. As was established earlier, structure formation processes proceed considerably more facile in mixtures subjected to deformations [15].

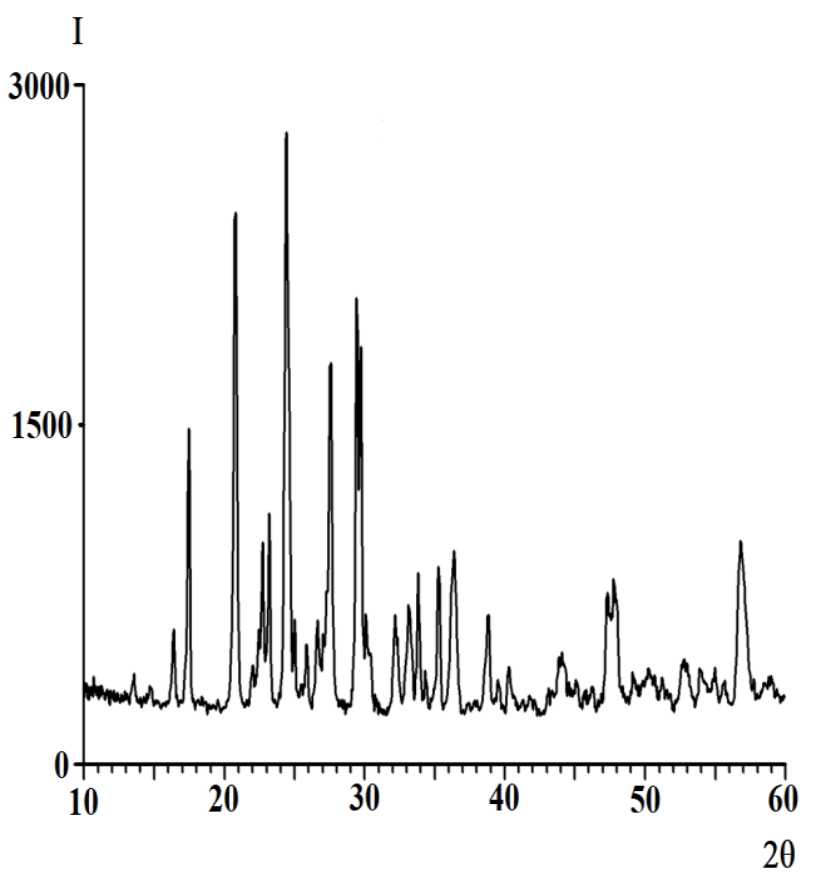

Fig. 6. X-ray diffraction pattern of lithium vanadium phosphate

Electrochemical tests were carried out for electrodes prepared using the active mass based on the $\mathrm{VPO}_{4}$ $\mathrm{Li}_{2} \mathrm{CO}_{3}$ mixture subjected to mechanical activation followed by annealing at $750^{\circ} \mathrm{C}$. The tests showed that our cathodes based on lithium vanadium phosphate displayed reversible cycling at current densities of 0.2$1.0 \mathrm{~mA} / \mathrm{cm}^{2}$. Figure 7 shows the $\mathrm{CV}$ curves of $\mathrm{Li}_{3} \mathrm{~V}_{2}\left(\mathrm{PO}_{4}\right)_{3}$ electrode at a scan rate of $0.1 \mathrm{mV} / \mathrm{s}$ from 3.0 to $4.3 \mathrm{~V}$.

\section{I, MA}

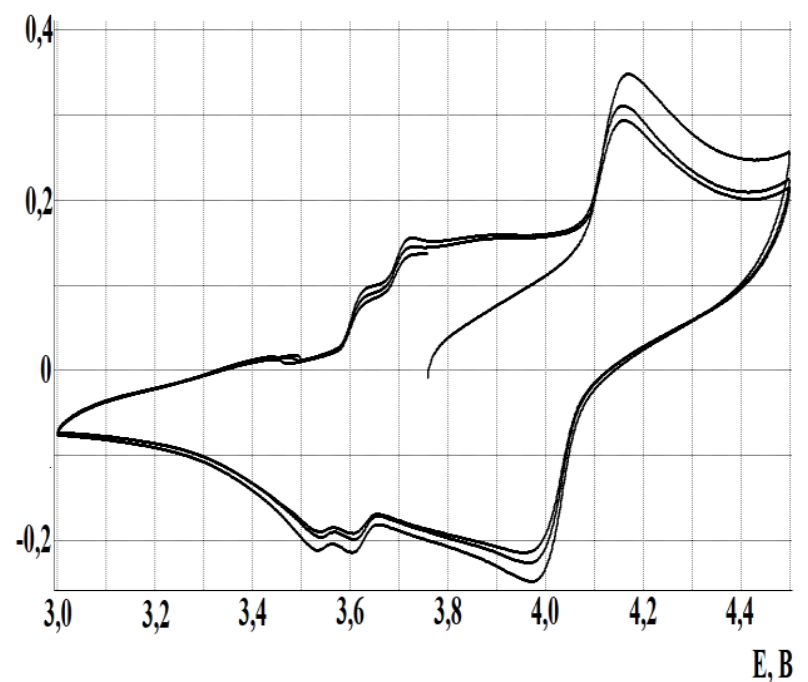

Fig. 7. Results of cyclic voltammetry analysis
Each of the CV curves includes three oxidation peaks and three reduction peaks, which is consistent with the galvanostatic charge/discharge curves. The good overlap of $\mathrm{CV}$ cycles and the symmetry of the oxidation and reduction peaks in the $\mathrm{CV}$ curves indicate the good reversibility of lithium insertion/deinsertion reactions.

A comparison of the results we obtained with published data demonstrated that electrodes based on $\mathrm{Li}_{3} \mathrm{~V}_{2}\left(\mathrm{PO}_{4}\right)_{3}$ synthesized in the study compare well in specific capacity and stability with the known foreign and domestic analogues $[5,9,10]$.

\section{Conclusions}

An original method for synthesis of lithium vanadium phosphate was developed. The method includes two stages: 1st, synthesis of vanadium phosphate from a mixture of ammonium dihydrophosphate and metal oxide; and 2st, synthesis of lithium iron phosphate by thermal lithiation of the product obtained in the 1st stage, which includes mechanical activation of the precursor in the course of plastic deformation. Our results would provide some basis for further improvement on the $\mathrm{Li}_{3} \mathrm{~V}_{2}\left(\mathrm{PO}_{4}\right)_{3}$ electrode materials.

\section{Acknowledgments}

The study was carried out under State assignment no.13.2052.2017/4.6 of the Ministry of Science and Higher Education of the Russian Federation.

\section{References}

1. C. Rozain, P. Millet Electrochimica Acta,EA 131. 160 (2014)

2. E. Mayousse, F. Maillard, F. Fouda-Onana, O. Sicardy, N. Guillet. Int J Hydrogen Energy.I.J. 36. 10474 (2011)

3. G. Liu, J. Xu, Y. Wang, J. Jiang, X. Wang Int J Hydrogen Energy. I.J. 39. 14531 (2014)

4. K. Zaghib, M Dontigny., A. Guerfi, Charest P. et al. J. Power Sources, J. P. 196.3949(2011).

5. A.Yaroslavtsev, T. Kulova, A.Skundin .Rusian Chemical Reviews. R. 84. 826(2015)

6. K. Smirnov, V. Zhorin , S. Smirnov . Inor. Materials: Appl. Res. I,5. 467(2014).

7. X. Yang, Z. Wenkui, H. Hui et al. J. Power Sources, J. P 196, 5651 (2011)

8. K. Smirnov, N. Yashtulov, G. Kuz'Micheva, V.Zhorin. Rus. J. of Appl. Chem. R. J.A.84, 1744 (2011)

9. N. Kosova , E. Devyatkina . Russ. J. Electrochem., Russ. J.E. 48, 320 (2012)

10. J. Chena, N. Zhaoa, F-F. Guob.Russ. J. Electrochem. Russ. J.E. 53, 339 (2017)

11. I. Vorob'ev, S. Smirnov jr., S. Smirnov., V. Zhorin. Russ. J. Appl. Chem. R. J.A.87, 734 (2014) 
12. I. Vorob'ev, K. Smirnov, S. Smirnov, V. Zhorin. Russ. J. Appl. Chem. R. J.A. 88.394 (2015)

13. S. Smirnov., V. Zhorin, M. Kiselev, S. Smirnov jr., N. Yashtulov. Inor. Materials: Appl. Res. I,9, 803 (2018)
14. V. Zlokazov, Chernyshev . J. Appl. Cryst. ,J. A. 25.447 (1992)

15. V. Zhorin, M. Kiselev, T. Puryaeva, S. Smirnov., . Protection of Metals and Physical Chemistry of Surfaces. P.M. 46. 96 (2010) 